\title{
De dependência em dependência: consentida, tolerada e desejada
}

\author{
PAUL SINGER
}

S

ITUAÇÕES DE DEPENDÊNCIA sempre haverá enquanto nações desiguais em desenvolvimento, tamanho, força etc. se mantiverem em estreito relacionamento mútuo. Mas estas situações diferem entre si e é isso o que importa. Fernando Henrique Cardoso (El proceso de desarrollo en América Latina: hipótesis para una interpretación sociológica, Santiago, Ilpes, nov.1965), num texto preliminar ao seu hoje famoso livro com Enzo Faletto, introduz o conceito de dependência nos termos: "A vinculação subordinada das economias subdesenvolvidas ao mercado mundial se manifesta no plano mais dinâmico do processo de desenvolvimento por uma série de características básicas no modo de atuação e na orientação dos grupos que aparecem no sistema econômico como produtores ou como consumidores. Esta situação de dependência supõe em suas situações extremas que as decisões que afetam a produção ou o consumo duma economia dada se tomam em função da dinâmica das economias desenvolvidas com as quais a economia subdesenvolvida mantém relações de dependência. As economias baseadas em enclaves coloniais constituem um exemplo extremo dessa situação" [sublinhado no original P.S.].

Como se vê, trata-se de dependência econômica de países independentes politicamente mas subdesenvolvidos, como os da América Latina, que, para se desenvolver, condicionam suas decisões "à dinâmica das economias desenvolvidas" de que dependem. A principal contribuição de Cardoso e Faletto para o melhor entendimento da questão foi apontar para situações distintas de dependência, mostrando que em cada uma se verifica uma correlação específica de força entre as classes sociais, tanto nos países desenvolvidos quanto nos subdesenvolvidos.

A dependência surge dum complexo jogo de conflitos e acordos entre classes e frações de classe, do qual resultam processos de desenvolvimento que recolocam, de tempos em tempos, os seus próprios fundamentos. Transformações do capitalismo, que em geral se originam no centro, ensejam o surgimento de novas situações de dependência, à medida que elas são incorporadas pela periferia.

\section{Da dependência consentida à dependência tolerada}

Depois que a América Latina se tornou independente, os donos das terras, das minas, do gado etc. tornaram-se, em cada país, a classe dominante, tendo ao seu lado uma elite de comerciantes e financistas que superintendia os canais que ligavam atividades agrícolas e/ou extrativas ao mercado mundial. A nova classe dominante via na dependência de seus países dos países capitalistas adiantados - até 
o último terço do século XIX, praticamente só o Reino Unido - o elo que os ligava à civilização da qual se acreditavam os únicos e autênticos representantes. Almejavam o progresso de seus países - a noção de desenvolvimento ainda não fora inventada - e só podiam concebê-lo como expansão contínua das atividades especializadas de exportação. Os elementos materiais e espirituais do progresso só eram alcançáveis mediante importação dos países civilizados para poder pagá-los havia que exportar.

Assim, é justo apelidar esta situação que se criou com a independência e que durou, em geral, até a Primeira Guerra Mundial, de dependência consentida. Ela se caracterizava pela ausência de qualquer dinâmica interna capaz de impulsionar o desenvolvimento. A maioria da população e do território estavam imersos em economia de subsistência. Quando o território era vasto, como no Brasil, na Argentina, na Colômbia ou no México, a tarefa primordial era unificá-lo mediante a construção de ferrovias, hidrovias e facilidades para a navegação de cabotagem. Além de linhas telegráficas e depois telefônicas, para tanto sendo impresciendível importar equipamento, know how e componentes.

Mas, a implantação desses serviços públicos só era financeiramente viável onde a produção para o mercado externo proporcionava um excedente monetário. Sob a forma de capital público ou privado, o desenvolvimento da infra-estrutura de serviços dependia diretamente do que cada região do país conseguia colocar no mercado mundial. Esta realidade era compreendida e aceita pelo conjunto da sociedade. Mesmo quando o país entrava em confronto com os países adiantados, a relação essencial de dependência jamais era questionada. Aparentemente, não havia alternativa ao desenvolvimento via crescente inserção subordinada no mercado mundial.

Um caso ilustrativo foi o confronto sobre o tráfico negreiro, que a GrãBretanha estava empenhada em combater em todo o mundo, mas que interessava vitalmente à classe dominante brasileira. Durante mais de 20 anos, o tráfico persistiu apesar das ações repressivas da marinha inglesa, que chegaram a interferir com a navegação de cabotagem no Brasil. Ao final, desencadeou-se, no Brasil, violenta onda nacionalista, que logicamente levaria a um choque bélico com a potência imperialista. Nesta altura, as melhores cabeças da oligarquia agro-exportadora brasileira resolveram reordenar as instituições legais - fizeram aprovar nova lei de terras e novo código comercial - para possibilitar a transição da economia do escravismo ao trabalho livre. Em 1850 o tráfico terminou, o confronto foi encerrado e a relação de dependência com a Grã-Bretanha preservada.

Os escravocratas brasileiros aceitaram eliminar as bases econômicas de sua dominação para não ter de abrir mão da dependência. Eles sabiam que sem contínuo abastecimento externo de cativos, a escravatura tinha os seus anos contados. Fizeram-no porque toda esperança de progresso que alimentavam para o país baseava-se na vinculação cada vez maior ao centro capitalista mundial, do qual o Reino Unido representava a maior parte. A dependência não era sentida nem ressentida como uma forma de subordinação, mas como um estágio pelo qual todos os retardatários tinham de passar. 
A situação só mudou quando, a partir da Primeira Guerra Mundial, a economia mundial entrou em fase de desglobalização. Entre 1914 e 1945, duas vastas e violentíssimas guerras mundiais, e uma longa e profunda crise econômica entre elas, destruíram as bases da divisão internacional do trabalho e do mercado mundial de capitais que vinham sendo desenvolvidas durante o século de paz que sucedeu ao fim das guerras napoleônicas. Verificou-se, nestas três décadas, uma desintegração da economia internacional: cada nação procurava importar o mínimo, estimulando a substituição dos produtos antes comprados no exterior por outros produzidos no país, ainda que piores e/ou mais caros. A produção mundial sofreu forte queda e o comércio internacional uma queda ainda pior.

Cumpre notar que esta vasta crise do capitalismo, e da globalização por ele ensejada, nada teve, em sua origem, a ver com os países menos desenvolvidos. Ela começou por um confronto bélico entre dois blocos imperialistas, culminou em crise financeira e profunda depressão, que se irradiou dos Estados Unidos (já então a principal potência imperialista) ao resto do mundo e terminou com um segundo conflito bélico mundial, mais longo, mais abrangente, mais destrutivo. Este último, diferentemente do primeiro, não foi interimperialista mas predominantemente ideológico: a extrema direita - o nazi-fascismo - empreendeu uma série de guerras de conquista que se tornou confronto ideológico quando atacou a União Soviética. Foi algo como uma vasta guerra civil mundial, em que democratas e stalinistas combateram lado a lado o totalitarismo de direita.

O fato que interessa, do ponto de vista da discussão da dependência, é a desglobalização ter atingido gravemente a dependência consentida ao contrair o mercado para os produtos exportados pelos países menos desenvolvidos. Este foram praticamente coagidos a seguir o exemplo dos países industrializados, lançando-se também à substituição de importações.

Em alguns países latino-americanos, notadamente Argentina, México, Brasil e Chile, já se havia iniciado uma industrialização por substituição de importações. Mas, esta era muito limitada, desenvolvendo apenas ramos nos quais o país dependente tinha vantagens comparativas, sem contar com significativa proteção aduaneira. As tarifas sobre importações tinham por finalidade apenas gerar receita fiscal. Elas não eram maiores devido à preocupação dos governos de que as nações industrializadas poderiam, em represália, gravar as importações provenientes de países com altas tarifas aduaneiras.

A desglobalização ofereceu à incipiente burguesia industrial dos países menos desenvolvidos uma oportunidade de ouro. O fechamento relativo dos mercados dos países industrializados tornou os países dependentes, para começar, inadimplentes, pois não dispunham de recursos para servir as suas dívidas externas; e depois, incapazes de continuar se abastecendo até mesmo de produtos essenciais, por falta de divisas com que pagá-las. Não lhes restava outra alternativa do que fazer da necessidade virtude e proclamar a industrialização, e não mais a exportação, a via mestre para o desenvolvimento. 
Essa mudança foi revolucionária em boa parte da América Latina. Ela começou com a Revolução Mexicana, iniciada em 1910, que se desdobrou por mais de uma década e instituiu um novo regime, declaradamente nacionalista, desenvolvimentista e industrializador. A Revolução de 1930, no Brasil, embora com outro desenrolar, instituiu um regime igualmente desenvolvimentista. Mudanças análogas ocorreram em outros países do continente entre os anos 30 e 50 . Em todas elas, a antiga oligarquia agro - ou extrativo-exportadora - expoente da dependência que chamamos de consentida - perdeu a hegemonia.

Seu lugar foi assumido pela burguesia industrial e por seus aliados, os empresários agrícolas, comerciais, bancários e de outros ramos, cujo mercado era predominantemente o interno. A experiência das duas guerras mundiais e da grande depressão dos anos 30 mostrou que era perfeitamente viável desenvolver economias semicoloniais mediante a substituição de importações. Desde que fosse possível contar com uma receita cambial suficiente para importar bens de capital, tecnologia e insumos indispensáveis à gradativa implantação de indústrias substituidoras de importações.

Neste sentido, numa primeira fase, continuaram importantes as exportações de frutos tropicais, minérios, matérias primas e demais commodities tradicionais. Quando a última guerra mundial acabou, as antigas oligarquias foram de certa forma reabilitadas. Os governos nacionalistas trataram de proteger fortemente os ramos industriais já instalados, mas ao mesmo tempo estimularam a retomada e expansão da antiga produção para o mercado externo, apossando-se das divisas que ela gerava para encaminhá-las às importações prioritárias à industrialização.

Passou-se assim a uma outra situação de dependência, que chamamos de tolerada. A nova classe dominante não enxergava a dependência com a mesma equanimidade da anterior. Diferentemente de antes, a partir da gradativa retomada da globalização, a nova dependência adquiria formas mais variadas e complexas. Os países em desenvolvimento passaram a depender dos industrializados para obter equipamentos e tecnologia, componentes e recursos de capital em larga escala. Esta dependência era vista pela nova classe dominante como essencialmente provisória, a ser superada tão logo a industrialização fizesse a economia emparelhar com as mais adiantadas.

A cada passo, o país dependente negociava com o país adiantado recursos destinados a diminuir a distância entre os dois e a permitir que o primeiro pudesse, no futuro, competir com o segundo. Na situação de dependência consentida, a divisão de trabalho entre centro e periferia não estava em questão. O progresso da periferia visava ao avanço de atividades agrícolas e extrativas que de modo geral não competiam com as que havia no centro. Por isso, a dependência era por suposto permanente. Na situação de dependência tolerada, o desenvolvimento almejado pela periferia destinava-se a revogar a divisão colonial de trabalho que a inferiorizava perante o centro. 
A passagem da dependência consentida à tolerada foi marcada por nítida ruptura ideológica. $\mathrm{Na}$ época da dependência consentida, a doutrina dominante era o livre-câmbio, racionalizado pela lei das vantagens comparativas. Os países retardatários deveriam crescer mediante a expansão dos ramos de produção em que eram favorecidos pela geografia e pela geologia. E que, por suposto, eram muito diferentes dos ramos em que os países industrializados tinham vantagens. $\mathrm{O}$ livre-comércio entre os países, através do jogo do mercado, levaria cada país a se especializar racionalmente, sendo todas as atividades igualmente geradoras de valor e portanto de utilidade e de bem-estar.

$\mathrm{Na}$ época da dependência tolerada, tornaram-se dominantes teorias como as elaboradas e divulgadas pela Cepal: centro e periferia têm participação qualitativamente diferente na economia internacional; enquanto o primeiro domina a produção de nova tecnologia, o que lhe permite adquirir o tempo todo novas vantagens comparativas, a segunda fica presa a um repertório limitado de vantagens comparativas decorrentes da disponibilidade de recursos naturais.

Outra diferença é que a economia industrial do centro é dominada por oligopólios e grandes sindicatos operários, os quais retêm os ganhos de produtividade, sob a forma de lucros extraordinários e aumentos reais de salários, ao passo que a economia rural da periferia é muito mais competitiva e por isso converte ganhos de produtividade em baixa de preços, o que transfere tais ganhos aos compradores, inclusive nos países adiantados. Daí a famosa tese Prebisch-Singer, segundo a qual a relação de intercâmbio entre centro e periferia tende, no longo prazo, a se deteriorar para a periferia

A nova ideologia desenvolvimentista propugnava a intervenção planejadora do governo para guiar e promover a industrialização. Os rumos do desenvolvimento não seriam dados pelos mercados mas por decisões políticas baseadas em planos de longo prazo para tornar os paises dependentes não mais dependentes mas plenamente industrializados. É neste sentido que a dependência, de consentida, passou a tolerada e pode-se até dizer mal tolerada. Teses, como a de Prebisch-Singer, insinuavam que no relacionamento comercial entre centro e periferia esta era explorada por aquele, o que tornava a situação de dependência intolerável no longo prazo.

Era a dependência tolerada o objeto de estudo e análise de Cardoso e Faletto, quando a teorizaram no fim dos 60 . Convém notar que tal situação de dependência co-existiu com a hegemonia do keynesianismo nos países adiantados. Também nesses países houve nítida ruptura ideológica, em função das experiências dos anos de guerra, crise e nova guerra. O liberalismo clássico foi substituído pela intervenção sistemática do governo na conjuntura econômica, tendo por objetivos atingir e garantir o pleno emprego e o crescimento que utilize plenamente os recursos de cada economia nacional.

A situação de dependência tolerada foi evoluindo, ao longo do período 194580, em função do avanço tanto da globalização dirigida quanto da própria indus- 
trialização nos países menos desenvolvidos. Convém lembrar que a globalização dirigida foi inaugurada pela Conferência de Bretton Woods, que criou as condições institucionais para a gradativa retomada da globalização com governos comandando economias nacionais mediante controle do comércio exterior e do câmbio, da moeda e dos juros, e do gasto fiscal ampliado por abrangente sistema de previdência pública e por um mais ou menos extenso setor produtivo estatal.

Até o fim da década de 50, a globalização foi caracterizada pela reconstrução dos países devastados pela guerra. Nas décadas seguintes, as EMNs [empresas multinacionais] dos Estados Unidos, que adquiriram uma posição de quase preponderância na nova indústria européia, passaram a sofrer a concorrência de suas congêneres da Europa ocidental e do Japão. A dependência tolerada adquiriu nova faceta, quando essas EMNs passaram a investir na indústria pesada em construção na América Latina e na Ásia. A partir dos 70, sucessivas rodadas de negociação sob o patrocínio do GATT lograram reduzir fortemente as barreiras alfandegárias que protegiam os mercados dos países industrializados. Esta abertura estimulou as trocas internacionais e as EMNs, assim como grandes empresas nacionais - públicas, privadas e mistas - passaram a exportar manufaturas a partir dos países em industrialização.

Estes fatos alteraram consideravelmente a situação de dependência tolerada. Cessou, para um bom número de países da periferia, a antiga dependência da exportação dos produtos extrativos ou agrícolas, que passaram a partir disso a ser conhecidos como NICs [newly industrialized countries - países recém-industrializados]. Para fugir aos custos mais elevados da força de trabalho, as EMNs transferiram dos países adiantados aos NICs setores industriais inteiros. A divisão internacional do trabalho diversificou-se mediante a diferenciação dos grupos de países em função do grau de desenvolvimento. Surgiram ao lados dos países desenvolvidos (cujo número se expandiu significativamente), países medianamente desenvolvidos, que o Banco Mundial ainda subdivide em três níveis - alto, médio e baixo e países menos desenvolvidos.

Convém notar que a partir desta época (os anos 70), os governos perderam grande parte do controle sobre o comércio exterior e também sobre o câmbio. Em 1971-76, o sistema internacional de pagamentos foi reformulado: quebrou-se a relação fixa de valor do dólar com o ouro e abandonaram-se as taxas relativamente fixas de câmbio, que passaram a flutuar com liberdade vigiada pelos bancos centrais. O chamado euro-mercado expandiu-se, surgindo um mercado financeiro internacional inteiramente fora do controle de autoridades governamentais ou intergovernamentais.

Não obstante tais mudanças, a dependência tolerada ainda governava as decisões dos países menos desenvolvidos. Com a notável exceção dos primeiros tigres asiáticos, a maioria dos países do Terceiro Mundo continuava dependendo do acesso de seus produtos aos mercados externos, dos financiamentos externos (crescentemente sob a forma de investimento direto estrangeiro) e das limitadas possibili- 
dades de internalizar a high tec, a tecnologia mais avançada, cujo desenvolvimento continuava circunscrito aos países adiantados.

\section{Da dependência tolerada à desejada}

A dependência tolerada começou a entrar em crise no Primeiro Mundo quando o capital privado recuperou a liberdade de que tinha sido privado pela revolução keynesiana. Esta, transformada em doutrina do poder, havia produzido os resultados esperados. Durante quase 30 anos (de 1945 a 73), as economias capitalistas se mantiveram próximas do pleno emprego, tiveram crescimento econômico mais rápido do que em qualquer outra época da história do capitalismo industrial e resgataram da pobreza a maior parte de suas classes trabalhadoras. Não por acaso, este período é chamado de os anos dourados.

Mas, nos três decênios, o capital e sobretudo o grande capital também se recuperou. Nos EUA, a potência hegemônica, o que prevaleceu foi a síntese neoclássica, uma versão que simplifica o quadro teórico deixado por lord Keynes e modera suas aplicações políticas. Praticamente, em todo pós-guerra, os EUA usaram sua considerável influência sobre o Fundo Monetário Internacional e o Banco Mundial para restabelecer a primazia do mercado na alocação dos recursos dentro das economias nacionais e para estabelecer a plena conversibilidade das moedas. A gradual liberalização financeira resultou em perda contínua da capacidade dos governos de controlar o excedente econômico, sua apropriação e seu investimento ou aplicação.

A liberalização financeira, a partir dos 80 , extravasou do Primeiro Mundo ao Terceiro. Foi importante, neste sentido, a crise do endividamento externo que atingiu grande número de países menos desenvolvidos, em particular na América Latina. Na década anterior, os grandes bancos privados multinacionais tinham aproveitado os vários choques do petróleo para captar, sobretudo no euro-mercado, muitos bilhões de dólares pertencentes aos países exportadores de petróleo, reciclando-os em seguida aos principais países em industrialização. A dependência financeira dos países menos desenvolvidos, até então dos bancos intergovernamentais, como o Banco Mundial, o Banco Interamericano, entre outros, passou a ser da banca multinacional privada.

Em 1982, o México sofreu uma severa fuga de capitais e deixou de servir sua dívida externa, o que colocava em perigo a existência dos bancos credores. Estes, por via das dúvidas, resolveram suspender empréstimos destinados aos demais países latino-americanos, o que tornou a maior parte deles inadimplente também. Mas, em vez do débacle bancário, que deveria seguir-se, o governo dos EUA juntamente com o Fundo Monetário Internacional e outras entidades intergovernamentais providenciaram empréstimos-ponte e, desse modo, evitaram que a crise financeira assumisse as dimensões catastróficas que atingira na década de 30.

A partir daí a tutela financeira e ipso facto política dos países semi-industrializados superendividados pelos EUA tornou-se muito mais pesada. Os países, que 
teimavam em manter o estatismo desenvolvimentista, foram boicotados pelo grande capital privado e público. Na Grã-Bretanha o governo Tatcher e nos EUA o governo Reagan comandavam a grande contra-ofensiva neoliberal, que foi largamente vitoriosa, inclusive na América Latina.

O primeiro Estado a abandonar toda pretensão a comandar a acumulação de capital em seu país foi o Chile, governado ditatorialmente nos anos 70 e 80 pelo general Pinochet. Em seguida, na América Latina, outros países enveredaram pelo mesmo caminho. No início dos 80, o México aboliu os controles cambiais e financeiros e abriu seu mercado interno às importações, recebendo em troca abundantes fluxos de capitais estrangeiros. Sua entrada posterior no Nafta apenas ratificou, em grande medida, uma situação que já há anos prevalecia de fato. Com a eleição de Menem, de Fujimori e de Collor, no fim da década de 80, chegou a vez da Argentina, do Peru e do Brasil. Nesses países, o desenvolvimentismo foi abandonado, o mercado interno aberto às importações de mercadorias e a economia à entrada incondicional dos capitais estrangeiros.

Do ponto de vista da situação de dependência, esta deixou de ser tolerada para se tornar desejada. Os governos de todos os paises - desenvolvidos, semidesenvolvidos ou pouco desenvolvidos - passaram a depender crescentemente do capital privado globalizado. Esta dependência é algo menor apenas nas grandes potências, cujas autoridades monetárias dispõem de algum controle sobre a taxa básica de juros e sobre o montante de crédito bancário e extra-bancário, podendo com tais instrumentos condicionar a movimentação dos capitais privados. Além disso, os governos das grandes potências têm por obrigação impedir que o grande capital, em sua corrida desvairada à centralização, ponha em perigo a própria existência do capitalismo pela completa monopolização dos mercados.

Abro um parêntese para assinalar que embora o assunto seja importante, a limitação de tempo e espaço me obriga a deixá-lo de lado. A tendência imanente do capital é se fundir crescentemente, até que em cada mercado haja apenas um vendedor. Mas isso significaria o fim da possibilidade de regular a economia pela competição intercapitalista e, portanto, do capitalismo como o conhecemos. Em seu lugar, teria de surgir uma economia regulada por mecanismo político. Os capitalista estão plenamente ao par deste perigo e apoiam os Estados que os impedem de se autodestruir.

Retomando o tema em análise, esta nova situação de dependência é de certa maneira uma volta à dependência consentida, mas com alterações não desprezíveis. É como se os 30 anos de desglobalização, somados aos 30 anos dourados, não passassem de um parêntese, que a restauração da normalidade, na forma de hegemonia do grande capital privado sobre a economia capitalista, poderia fechar. A subordinação dos estados nacionais aos interesses e aos preconceitos ideológicos dos detentores do grande capital globalizado restabeleceria uma normalidade que fora perturbada por peripécias políticas, passageiras. 
A tese é sedutora, sobretudo para os aficcionados da história, que não desconhecem as evidentes afinidades entre o fin de siècle anterior e o atual. Mas, é preciso também atentar para as diferenças. Para começar, atualmente a democracia é o regime da maioria dos países, significando que o desemprego e a exclusão social, normalmente exacerbados pela liberdade do capital, não são politicamente aceitáveis. No fim do século passado, desemprego e exclusão social pareciam fatalidades inevitáveis, presentes em todas as épocas históricas. Neste fim de século, está claro que o desemprego e a exclusão social puderam ser efetivamente reduzidos durante os anos dourados e que, portanto, nada têm de inevitáveis, o que explica a crescente revolta contra o neoliberalismo, tanto na Europa quanto na América Latina.

Outra diferença significativa entre os dois fins de século é que agora estamos efetivamente formando um mundo de nações. Há cem anos, a maior parte do mundo era constituída por colônias de um pequeno número de potências imperialistas. Hoje não há mais colônias quase e o mundo se compõe de mais de 180 nações soberanas. É óbvio que são extremamente heterogêneas, distinguindo-se pelo tamanho dos territórios e das populações, pelo grau de desenvolvimento e por inúmeras características culturais.

Por isso, cabe menos generalizar, inclusive com relação a situações de dependência. Certamente, hoje existem em diferentes países as três situações de dependência que distinguimos. Grande parte das nações africanas e não poucas da Ásia e da América Latina vivem em dependência consentida, no sentido de que suas perspectivas de progresso ainda estão limitadas à ampliação das vendas ao exterior de produtos coloniais. Outras nações, espalhadas pelos três continentes do Terceiro Mundo, já superaram essa etapa e dispõem de economias ainda não-completamente industrializadas. São os países que vivem situações de dependência tolerada ou de dependência desejada.

A diferença entre a dependência consentida - absolutamente geral no fim do século XIX e hoje vigente apenas nos países mais atrasados - e a dependência desejada é que a primeira prescinde da industrialização e da urbanização e a última visa completar estes processos para incorporar as nações dependentes ao Primeiro Mundo. Não há, portanto, qualquer volta possível a uma normalidade liberal como a que vigorou no século XIX. A nova dependência do grande capital globalizado é desejada porque vista como um ingrediente indispensável num mundo em que as nações perdem significado econômico e em que impera a liberdade de iniciativa das empresas e dos indivíduos.

A dependência desejada ocorre hoje em todas as nações, das semi-industrializadas às superindustrializadas. Esta é a mudança essencial que é preciso analisar. Durante a época da globalização dirigida (1945-80), os países menos desenvolvidos dependiam economicamente tanto dos capitais multinacionais provenientes dos países adiantados quanto dos governos desses países, em particular do governo dos EUA. Grande parte do fluxo de financiamentos recebidos pelos países dependentes se originava de fontes públicas nacionais ou intergovernamentais (como o Banco Mundial, o Banco Interamericano e seus congêneres da Ásia e da África). 
Mas, os governos dos países adiantados não se subordinavam ao grande capital, fosse este nacional ou estrangeiro. No auge do keynesianismo, mesmo bastardo, como o adjetivou Joan Robinson, os Estados nacionais dispunham de amplos setores produtivos estatais, que abrangiam os principais serviços de infra-estrutura e partes da indústria pesada. Somava-se a ele um sistema abrangente de seguridade social, o que levava a participação do setor público no PIB a se aproximar de 50\%, sobretudo nos países europeus. Esse contexto permitia aos governos regular a conjuntura apenas pela modulação do gasto público.

A mudança a partir dos anos 70 foi gradativa mas, passados 25 anos, o panorama é outro. Ela tem por motor a globalização do capital, que ocasionou uma transformação da classe dominante. O setor dominante da classe capitalista, na maior parte dos países desenvolvidos (exceto os EUA e o Reino Unido) estava ligado umbelicalmente ao mercado interno. No Japão, na França, mas também na Alemanha Ocidental e na Itália, Estado e capital nacional tinham construído uma coordenação eficaz e mutuamente satisfatória, na qual a burocracia estatal estabelecia metas e estratégias de médio e longo prazos e convidava a iniciativa privada a realizálas, com meios providos por bancos governamentais e subsídios pagos pelo orçamento nacional.

Com a globalização tanto de intermediários financeiros quanto de empresas industriais, o setor dominante - formado antes e depois pelas maiores empresas da classe capitalista passou a ser composto por detentores do controle e da gerência de empresas que tinham interesses nos quatro cantos do mundo e cujas vantagens comparativas derivavam desse fato. Em cada país, com o mercado interno aberto aos capitais e aos produtos do resto do mundo, os ganhadores do jogo competitivo passaram a ser os capitais multinacionais, que mais podiam importar matérias primas, componentes e produtos acabados de filiais em países atrasados e de trabalho barato.

A mudança de hegemonia econômica foi acompanhada por uma ruptura ideológica de todas as maneiras funcional. Em poucos anos, a nova fração capitalista dominante substituiu o keynesianismo pelo monetarismo, o dirigismo econômico pelo neoliberalismo. Com rapidez surpreendente o consenso mudou. O pleno emprego passou a ser uma meta inatingível e os esforços para mantê-la próxima dele passaram a ser tidos como causas da estagflação. A nova ortodoxia sustenta agora que os mercados, deixados em liberdade, ou seja, livres da tutela estatal, praticamente sempre alcançam equilíbrios ótimos.

O desemprego, qualquer que seja o seu nível, é sempre voluntário: as pessoas que alegam falta de trabalho, na realidade não aceitam os níveis de remuneração que o mercado oferece e elas têm direito de estar desempregadas até que encontrem a demanda que lhes pague o que acham que valem. Esta teoria foi formulada por Milton Friedman e é encontrada hoje nos livros-texto utilizados no ensino nas faculdades de economia. Ela obviamente é desconhecida do grande público, que sabe que o desemprego é uma maldição e que considerá-lo voluntário só pode ser 
humor negro. Mas a teoria, acessível apenas a iniciados, fundamenta as políticas econômicas aplicadas em cada vez mais países desde os anos 80 .

Os governos que compartilham desta nova/velha ideologia desejam a dependência dos capitais globalizados. O neoliberalismo defende a liberdade dos mercados contra qualquer interferência política neles porque acredita que os detentores dos capitais - principalmente os administradores de grandes blocos de riqueza financeira, como os fundos de pensão e as reservas técnicas das seguradoras têm racionalidade e dispõem de todas as informações necessárias para investir os capitais de modo a maximizar o bem-estar social global.

Esses governos desejam se submeter aos critérios dos detentores de capitais para merecer as suas preferências. Estes critérios são: manter plena liberdade de movimento para os capitais, assegurar o equilíbrio orçamentário e a estabilidade dos preços, deixar o câmbio flutuar mas dentro de limites pré-fixados, liberar o mercado de trabalho de restrições à livre contratação e entregar à iniciativa privada a prestação de serviços públicos, da telefonia ao seguro saúde e ao seguro social. Os governos neoliberais almejam cumprir tais objetivos por convicção e acreditam que merecem a preferência do capital globalizado.

A dependência desejada é qualitativamente distinta das situações anteriores de dependência à medida que estas últimas atingiam unicamente as nações menos desenvolvidas. $\mathrm{O}$ atraso econômico relativo era a base da qual decorria a situação de dependência. A atual situação de dependência reflete a impotência dos Estados nacionais - em maior ou menor medida, todos - face ao capital privado altamente concentrado e globalizado. Esta impotência se deve mais à globalização do capital do que à liberalização dos movimentos de valores.

É que as empresas autenticamente transnacionais não são mais firmas de algum país adiantado que abriu filiais no Terceiro Mundo. Elas já são - e tendem cada vez mais a ser - firmas sediadas em quase todos os países, sobretudo nos adiantados. E como são frutos de sucessivas fusões e aquisições, muitas delas têm suas matrizes em mais de um país. Antigamente, a Shell e a Lever eram dois exemplos conhecidos de empresas binacionais, pois ambas são anglo-holandesas. Mas, eram exceções. Atualmente estão se tornando a regra entre os conglomerados maiores.

A trilateralização das transnacionais está sendo impulsionada pela concorrência tecnológica entre elas. Há dados que indicam que os custos de novos desenvolvimentos tecnológicos estão subindo muito, o que provavelmente significa que a exploração das novas técnicas está entrando numa fase de rendimentos decrescentes. Este seria o fator que levaria as grandes firmas transnacionais a se fundir ou a se associar, de modo a poder participar da produção científica de todos os grandes centros em atividade nas economias mais adiantadas.

A dependência desejada, se estas hipóteses estiverem corretas, decorre crescentemente da não coincidência territorial entre o âmbito de atividades das grandes transnacionais e o âmbito de exercício da soberania dos governos. As grandes 
transnacionais tendem a assumir a forma de empresa-rede, composta por grande número de unidades semi-autônomas - empresas franqueadas, subcontratadas, em parceria etc. - enquanto os Estados nacionais estão apenas começando a se agrupar em blocos regionais. A União Européia é destes blocos o mais antigo, no qual o processo de unificação econômica, social e política está mais avançado. Mesmo na União Européia, no entanto, a integração intergovernamental ainda é incipiente se comparada com a integração em rede de empresas em todos os quadrantes.

Para terminar esta breve discussão das tendências atuais da dependência é preciso lembrar que, não obstante tudo isso, as pessoas continuam morando, trabalhando e fazendo política em países específicos. Para a maioria da população, a dependência desejada se traduz em crises de reestruturação industrial, que eliminam milhões de postos de trabalho, e ataques reiterados a direitos decorrentes do Estado de bem-estar social, cuja única justificativa é a necessidade de equilibrar o orçamento público e reduzir a carga fiscal sobre as empresas para reter o capital que se encontra no país e atraír mais capital, que venha eventualmente a gerar emprego.

Não é provável que a maioria dos cidadãos dos diferentes países - muito, pouco ou medianamente desenvolvidos - aceite passivamente tal justificativa. O que configura um dilema: ou os países ampliam o território em que seus Estados exercem a soberania, acelerando sua unificação política ou ao menos fortalecendo entidades intergovernamentais que possam confrontar e regular as grandes transnacionais, ou a nova dependência corroerá a democracia política, ao retirar da agenda política das nações as questões que mais de perto interessam aos cidadãos.

Paul Singer, economista, é professor da Faculdade de Economia e Administração da Universidade de São Paulo. 